\title{
Life Style-Related Disease and Colorectal Cancer
}

\author{
Hirokazu Takahashi and Masahiko Inamori
}

Key words: colorectal cancer, obesity, smoking

(Inter Med 48: 121, 2009)

(DOI: 10.2169/internalmedicine.48.1800)

Chronic conditions including obesity, diabetes, hyperlipidemia and hypertension have been shown to be associated with a Western diet, alcohol intake, and smoking. Indeed, obesity has been reported to be associated with an elevated risk of cardiovascular disease, diabetes and mortality. Recently, these life styles have also been shown to be correlated with an increase in colorectal cancer (CRC) risk. CRC is a disease with a high mortality and morbidity rate, and recently its prevalence has been increasing worldwide. In their recent report in the journal (1), Omata et al suggested that a body mass index (BMI) of 22-25, associated with both colorectal neoplasms including CRC and hyperplastic polyps (HP), and current or heavy smoking, is in part correlated with colorectal neoplasms (CRN) and HP.

Obesity, hyperinsulinemia and insulin resistance have been repeatedly shown to be associated with CRC and colorectal precancerous lesions $(2,3)$. Overweight, obesity, or high BMI has been consistently associated with an increased risk for CRC incidence and mortality, at least in men and premenopausal women (4). The WHO definition of life style-related disease allows the use of a BMI of at least 30 $\mathrm{kg} / \mathrm{m}^{2}$ in place of waist circumference or waist-to-hip ratio (5).

Diabetes mellitus (DM) and hyperlipidemia were also associated with an increased risk for CRC in cohort studies (6-10). A recent study reported that diabetic individuals, especially those who are obese, have an increased risk of prevalent colon adenoma and particularly for advanced adenoma (11). Recently, great progress has been made in understanding the role of life style-related diseases and CRC. CRC is potentially one of the most preventable malignancies (12). Further research may lead to new opportunities for prevention of CRC.

\section{References}

1. Omata F, Brown RW, Tokuda Y, et al. Modifiable risk factors for colorectal neoplasms and hyperplastic polyps. Intern Med 48: 123128, 2008.

2. Limburg PJ, Anderson KE, Johnson TW, et al. Diabetes mellitus and subsite-specific colorectal cancer risks in the Iowa Women's Health Study. Cancer Epidemiol Biomarkers Prev 14: 133-137, 2005.

3. Takahashi H, Yoneda K, Tomimoto A, et al. Life style-related diseases of the digestive system: colorectal cancer as a life stylerelated disease: from carcinogenesis to medical treatment. J Pharmacol Sci 105: 129-132, 2007.

4. Giovannucci E, Michaud D. The role of obesity and related metabolic disturbances in cancers of the colon, prostate, and pancreas. Gastroenterology 132: 2208-2225, 2007.

5. World Health Organization. Definition, diagnosis, and classification of diabetes mellitus and its complications: report of a WHO consultation. Geneva: World Health Organization: 1999.

6. Ahmed RL, Schmitz KH, Anderson KE, Rosamond WD, Folsom AR. The metabolic syndrome and risk of incident colorectal cancer. Cancer 107: 28-36, 2006.
7. Yamada K, Araki S, Tamura M, et al. Relation of serum total cholesterol, serum triglycerides and fasting plasma glucose to colorectal carcinoma in situ. Int J Epidemiol 27: 794-798, 1998.

8. Bayerdorffer E, Mannes GA, Richter WO, et al. Decreased high density lipoprotein cholesterol and increased low-density cholesterol levels in patients with colorectal adenomas. Ann Intern Med 118: 481-487, 1993.

9. Park SK, Joo JS, Kim DH, Kim YE, Yang D, Yoo KY. Association of serum lipids and glucose with the risk of colorectal adenomatous polyp in men: a case-control study in Korea. J Korean Med Sci 15: 690-695, 2000.

10. Wang YY, Lin SY, Lai WA, Liu PH, Sheu WH. Association between adenomas of rectosigmoid colon and metabolic syndrome features in a Chinese population. J Gastroenterol Hepatol 20: 1410-1415, 2005.

11. Elwing JE, Gao F, Davidson NO, Early DS. Type 2 diabetes mellitus: the impact on colorectal adenoma risk in women. Am J Gastroenterol 101: 1866-1871, 2006.

12. Rougier P, Mitry E. Epidemiology, treatment and chemoprevention in colorectal cancer. Ann Oncol 14: ii3-ii5, 2003. 